\title{
Determination of Berberine Content in the Stem Extracts of Coscinium fenestratum by TLC Densitometry
}

\author{
Piyanuch Rojsanga $^{a} \quad$ Wandee Gritsanapan $^{a}$ Leena Suntornsuk ${ }^{b}$ \\ Departments of a Pharmacognosy and ${ }^{b}$ Pharmaceutical Chemistry, Faculty of Pharmacy, Mahidol University, \\ Ratchatawi, Bangkok, Thailand
}

\section{Key Words}

Berberine $\cdot$ Coscinium fenestratum $\cdot$ Thin-layer

chromatography-densitometry

\begin{abstract}
Objective: To develop the optimal extraction procedure (i.e. maceration, percolation or Soxhlet extraction) and thinlayer chromatographic (TLC)-densitometric method for the determination of berberine content of Coscinium fenestratum. Materials and Methods: Maceration, percolation and Soxhlet extraction techniques were used to extract alkaloids from dried stems of $C$. fenestratum. The solvents used were 50 and $80 \%$ ethanol. Crude extracts and berberine content recovered from the TLC fingerprint were evaluated for chemical components of each extraction method. Precoated silica gel $\mathrm{GF}_{254}$ plates were used as stationary phase while butanol:glacial acetic acid:water (14:3:4) was used as a mobile phase. Detection and quantitation of berberine were performed by densitometry at the wavelength of $415 \mathrm{~nm}$ over the linearity range of $240-840 \mathrm{ng}\left(\mathrm{r}^{2}=0.9982\right)$. The relative standard deviations from intraday and interday precisions were less than $4.13 \%$. Results: The recovery of standard berberine was $97.58-98.71 \%(\% \mathrm{RSD}=3.85)$, and the limit of detection and quantitation were 25 and $50 \mathrm{ng} /$ spot, respectively. Eighty percent ethanol gave a higher
\end{abstract}

\section{KARGER}

Fax +4161306 1234

E-Mail karger@karger.ch

www.karger.com
(C) 2006 S. Karger AG, Basel

$1011-7571 / 06 / 0155-0373 \$ 23.50 / 0$

Accessible online at:

www.karger.com/mpp content of berberine than $50 \%$ ethanol. Berberine contents from maceration, percolation and Soxhlet extraction with $80 \%$ ethanol were $3.37 \pm 0.30,3.08 \pm 0.38$ and $2.67 \pm 0.27 \%$ $\mathrm{w} / \mathrm{w}$, respectively. Conclusion: The TLC-densitometric method was simple, accurate and precise for quantitating berberine in the stem extract of $C$. fenestratum. Maceration with $80 \%$ ethanol gave the highest content of berberine in the extract. TLC of the extracts from different methods showed a similar pattern.

Copyright $\odot 2006$ S. Karger AG, Basel

\section{Introduction}

Coscinium fenestratum (Gaertn.) Colebr. (Menispermaceae) is called 'Hamm' in Thai language $[1,2]$. It is a traditional medicine of the northeastern part of Thailand which is recently very popularly used. This plant is a woody climbing shrub with cylindrical stem. Its stem is claimed for balancing blood pressure, being a detoxifying and antidiabetic agent and for treatment of hypercholesterolemia.

Pharmacological studies have shown that C. fenestratum has antifungal, antiyeast, antibacterial, hypotensive and antiproliferative activities [3-7]. The major components in wood and root of $C$. fenestratum are isoquinoline 


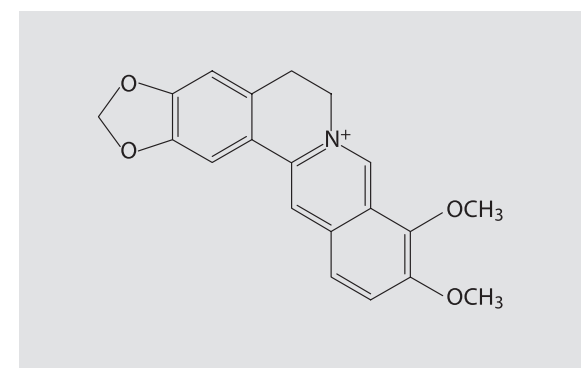

Fig. 1. Structure of berberine.

alkaloids such as berberine (fig. 1), palmatine, tetrahydropalmatine, crebanine and jatrorhizine, while berberine is found to be the major and active constituent $[8,9]$. The berberine content in C. fenestratum has not been reported elsewhere.

Thus, the aims of this experiment were to develop a thin-layer chromatographic (TLC)-densitometric method for the determination of berberine content in the stem extracts of $C$. fenestratum and to determine the optimum extraction procedure (maceration, percolation or Soxhlet extraction), which provides extracts enriched in berberine content. Comparison of the extracts was based on the yield of the crude extracts and berberine content. TLC fingerprint of the extracts from different methods was performed.

\section{Materials and Methods}

\section{Reagents}

Berberine chloride dihydrate was purchased from Sigma (St. Louis, Mo., USA). Butanol, glacial acetic acid and formic acid were of analytical grade obtained from Labscan Asia (Bangkok, Thailand). Methanol and ethyl acetate were obtained from Fisher Scientific (Leicestershire, UK). All other chemicals were of analytical grade and were used without further purification. Deionized water was used in all preparations.

The dried stems of $C$. fenestratum were purchased from the Udonthani province in the Northeast of Thailand in January 2004. The stem was chopped into small pieces and dried in a hot air oven $\left(50^{\circ} \mathrm{C}\right)$. The sample was ground and passed through a sieve with mesh number 20 . The powdered sample was pharmacognostically identified (macroscopic, microscopic and TLC characteristic) and compared to the reference [2].

\section{Extraction Method}

Different extraction methods, i.e. maceration, percolation and Soxhlet extraction, were compared for the preparation of crude extracts containing high content of berberine from the stem of C. fenestratum. Each method was performed in triplicate.
For maceration, the powdered plant material (30 g) was separately macerated with 50 and $80 \%$ ethanol $(500 \mathrm{ml}$ each) for 7 days with occasional shaking. The extract was filtered through Whatman filter paper No. 1. The marc was reextracted exhaustively $(300 \mathrm{ml} \times 5)$.

Percolation was carried out using the powdered plant material $(30 \mathrm{~g})$, which was separately mixed with $10 \mathrm{ml}$ of 50 or $80 \%$ ethanol. The mixture was allowed to stand for $1 \mathrm{~h}$, and then transferred to a percolator to which the same solvent was added (totally 5 liters). The percolation was set at a flow rate of $1.5 \mathrm{ml} / \mathrm{min}$. The extraction was stopped when the percolate was exhaustively extracted and the extractant was colorless.

For Soxhlet extraction, the powdered plant material (30 g) was exhaustively extracted with $80 \%$ ethanol $(300 \mathrm{ml} \times 2)$ in a Soxhlet apparatus at $80^{\circ} \mathrm{C}$ for $72 \mathrm{~h}$.

The combined extract of each extraction was filtered and evaporated to dryness on a water bath set at $100^{\circ} \mathrm{C}$. The dried residue of each extract was cooled in a desiccator for $30 \mathrm{~min}$ and then accurately weighed for analysis.

\section{Preparation of Standard and Sample Solutions}

A stock solution of berberine was prepared by dissolving $4.8 \mathrm{mg}$ of standard berberine chloride dihydrate (equivalent to $3.96 \mathrm{mg}$ of berberine) in $10 \mathrm{ml}$ methanol. The standard solution of berberine was prepared by diluting the stock solution to obtain the concentration of $99 \mu \mathrm{g} / \mathrm{ml}$.

The sample solution was prepared by weighing dried extracts from each method $(10 \mathrm{mg})$, dissolving in each extracting solvent and adjusting to $10 \mathrm{ml}$.

\section{Chromatographic Procedure}

A Camag TLC system consisting of a TLC Scanner III, application device Linomat IV, twin trough plate development chamber, winCATS 1.2.6 software (Camag, Muttenz, Switzerland) were used. Chromatography was performed on silica gel $\mathrm{GF}_{254}$ plates $(20 \times 10 \mathrm{~cm}, 0.2 \mathrm{~mm}$ thickness, E. Merck, Germany) with a 100- $\mu$ l Camag syringe. The samples were streaked as narrow bands of length 6 and $10 \mathrm{~mm}$ from the lower edge using a nitrogen aspirator. Development of the plates was carried out allowing $9 \mathrm{~h}$ for solvent saturation of the tank at ambient temperature. A solvent system consisting of butanol:glacial acetic acid:water (14:3:4, $\mathrm{v} / \mathrm{v} / \mathrm{v})$ was used. Total volume of solvent mixture was $30 \mathrm{ml}$ and the migration distance was $80 \mathrm{~mm}$. Chromatograms were evaluated via peak area after scanning in absorbance mode at $415 \mathrm{~nm}$ with a scanning speed of $20 \mathrm{~mm} / \mathrm{s}$ using a slit dimension of $5 \mathrm{~mm}$ $\times 0.45 \mathrm{~nm}$.

\section{TLC Fingerprint}

A solution of each extract was prepared to obtain the concentration of $10 \mathrm{mg} / \mathrm{ml}$ using the same extractant. The extract $(3 \mu \mathrm{l})$ and the standard solutions $(0.396 \mathrm{mg} / \mathrm{ml}, 5 \mu \mathrm{l})$ were spotted on TLC plates. The plate was developed in two solvent systems, which were butanol/glacial acetic acid/water 14:3:4 and ethyl acetate/butanol/formic acid/water 50:30:12:10 to a distance of $80 \mathrm{~mm}$. After removing the plate from the chamber, the plate was air-dried in a fume hood for $30 \mathrm{~min}$ and examined under ultraviolet light (254 and $366 \mathrm{~nm}$ ). The plate was sprayed with Dragendorff's spraying reagent. Separately, the plate was sprayed with anisaldehyde-sulfuric acid reagent and heated at $110^{\circ} \mathrm{C}$ for $10 \mathrm{~min}$. 
Table 1. Yield of crude extract and berberine content in the stem extracts of C. fenestratum by several methods

\begin{tabular}{llll}
\hline Extract & $\begin{array}{l}\text { Extraction } \\
\text { time, days }\end{array}$ & $\begin{array}{l}\text { Yield of crude } \\
\text { extract, \%w/w }\end{array}$ & $\begin{array}{l}\text { Berberine content } \\
\% w / w\end{array}$ \\
\hline Macerated in 50\% ethanol & 60 & $18.13 \pm 0.07$ & $2.38 \pm 0.11$ \\
Macerated in 80\% ethanol & 60 & $18.41 \pm 0.16$ & $3.37 \pm 0.30$ \\
Percolated in 50\% ethanol & 30 & $18.13 \pm 1.27$ & $2.97 \pm 0.31$ \\
Percolated in 80\% ethanol & 30 & $17.37 \pm 1.85$ & $3.08 \pm 0.38$ \\
Soxhlet in 80\% ethanol & 3 & $16.12 \pm 0.10$ & $2.67 \pm 0.27$ \\
\hline
\end{tabular}

Values are expressed as mean $\pm \mathrm{SD}$. Analysis was done in triplicate.

\begin{tabular}{|c|c|c|}
\hline \multirow[t]{2}{*}{ Characteristics } & \multicolumn{2}{|l|}{ Result } \\
\hline & major component & standard berberine \\
\hline \multirow[t]{2}{*}{$\mathrm{R}_{\mathrm{f}}$ value } & 0.55 (system 1$)$ & 0.55 (system 1$)$ \\
\hline & 0.65 (system 2) & 0.65 (system 2 ) \\
\hline Short wavelength $(254 \mathrm{~nm})$ UV light & quenching (orange) & quenching (orange) \\
\hline Long wavelength (366 nm) UV light & fluorescence (yellow) & fluorescence (yellow) \\
\hline Dragendorff s spray reagent & orange & orange \\
\hline Anisaldehyde-sulfuric acid reagent & yellow & yellow \\
\hline
\end{tabular}

Table 2. Characteristics of the major component and standard berberine in TLC fingerprints of the stem extracts of $C$. fenestratum

\section{Results and Discussion}

The method linearity was determined by using a standard solution of $120 \mu \mathrm{g} / \mathrm{ml}$ in methanol $(\mathrm{n}=3)$. Two to $10 \mu \mathrm{l}$ of standard solution were applied on the plate corresponding to concentrations of $240-1,200 \mathrm{ng} / \mathrm{spot}(\mathrm{n}=3)$. The accuracy of the method was tested by performing the recovery studies. Three different volumes $(1,1.5$ and $2 \mathrm{ml}$ ) of the standard solution (containing $0.48 \mathrm{mg} / \mathrm{ml}$ of berberine in methanol) were added to the sample solution of macerated $80 \%$ ethanolic extract $(860 \mathrm{mg} / \mathrm{ml})$ and analyzed by the TLC-densitometric method. The percentage recovery as well as the average percentage recovery was calculated. The precision of the method was tested by analyzing $480 \mathrm{ng} / \mathrm{spot}$ of standard solution of berberine after application on a TLC plate $(n=6)$ on the same day for intraday precision and on 3 different days for interday precision by the proposed method. The percent relative standard deviation (\%RSD) was calculated. Limit of detection (LOD) and quantitation (LOQ) were determined by scanning the blank spot and noise [10]. Series of concentrations of the solution (10-100 ng/spot) were spotted on the plate. The signalto-noise ratio of 3 and 10 were considered as LOD and LOQ, respectively.

Determination of Berberine Content in the Stem Extracts of C. fenestratum

A volume of sample solution $(5 \mu \mathrm{l})$ was applied in triplicate on a TLC plate and analyzed by the proposed method. The amount of berberine in the sample was calculated using the calibration curve for berberine.

\section{Comparison of Extraction Methods}

The yields of crude extract from each extraction method were not significantly different $(\mathrm{p}<0.05)$ (table 1$)$. The highest yield was obtained from maceration with $80 \%$ ethanol, followed by maceration and percolation with $50 \%$ ethanol. Percolation with $80 \%$ ethanol and the Soxhlet extraction with $80 \%$ ethanol gave lower yields. The maceration with $80 \%$ ethanol gave the highest yield and this might be because the compounds in the stem of C. fenestratum are medium polar compounds. Therefore, they could be extracted by $80 \%$ ethanol better than by $50 \%$ ethanol. Although the highest yield was obtained with maceration, however the extraction time was longer than that of other methods.

The TLC fingerprints of each extract were similar and the major component of all extracts was berberine with the $R_{f}$ value of 0.55 for solvent system 1 and 0.65 for solvent system 2 (table 2). Berberine showed yellow fluorescence under UV $366 \mathrm{~nm}$. The chromatograms of standard berberine and tested samples are shown in figures $2 \mathrm{a}$ and $\mathrm{b}$, respectively. 
Fig. 2. Chromatograms of berberine standard and $80 \%$ ethanolic extract of C. fenestratum. a Berberine standard (396 ng/ spot). b $80 \%$ ethanol extract of C. fenestratum.

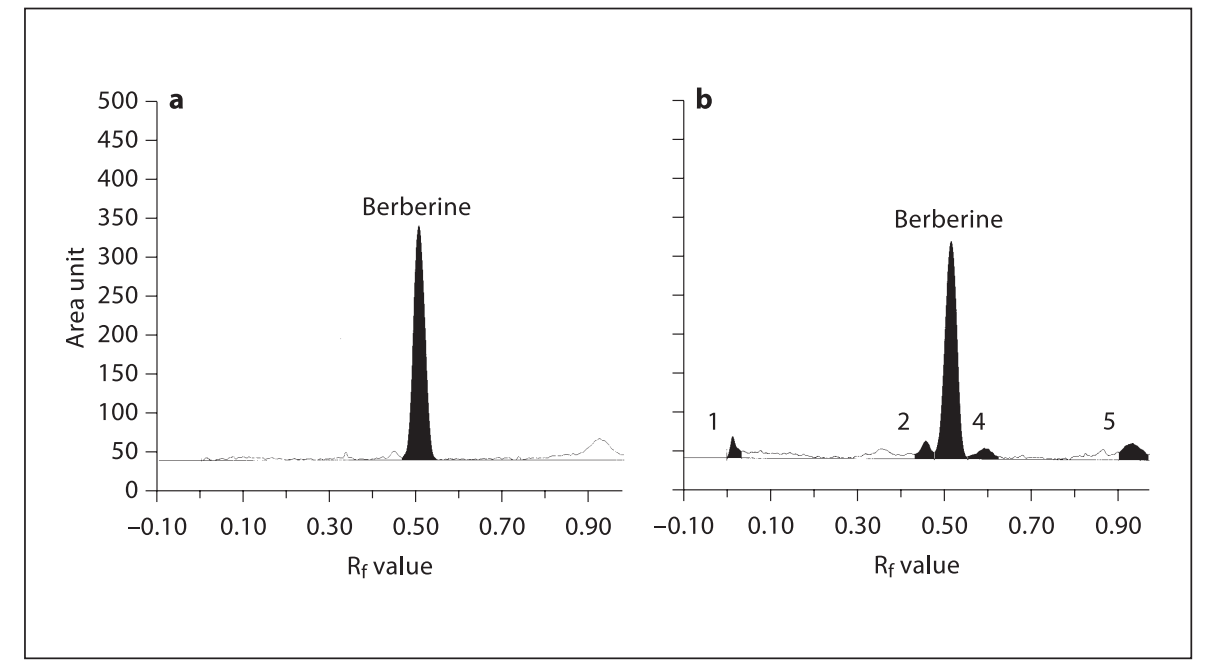

Table 3. Calibration curve parameters and statistics of berberine $(\mathrm{n}=3)$ at the concentration range of $198-693 \mathrm{ng} / \mathrm{spot}$

\begin{tabular}{llll}
\hline Curve & Slope & y intercept & $\mathrm{r}^{2}$ \\
\hline 1 & 9.0819 & 779.62 & 0.9982 \\
2 & 9.4771 & 672.87 & 0.9966 \\
3 & 9.1134 & 824.85 & 0.9985 \\
Mean & 9.2241 & 759.11 & \\
SD & 0.2196 & 78.04 & \\
RSD, \% & 2.38 & 10.28 & \\
\hline
\end{tabular}

Fig. 3. Overlay of UV spectra of berberine standard and berberine in sample.

\section{Method Validation}

TLC-densitometric method was validated for its linearity, accuracy, precision, limit of detection and quantitation. The method is specific as berberine was well resolved from other components with $\mathrm{R}_{\mathrm{f}}$ value of 0.55 (system 1) without interference by other components in samples. An excellent linear relationship was obtained within the concentration range of $240-840 \mathrm{ng} / \mathrm{spot}$ for

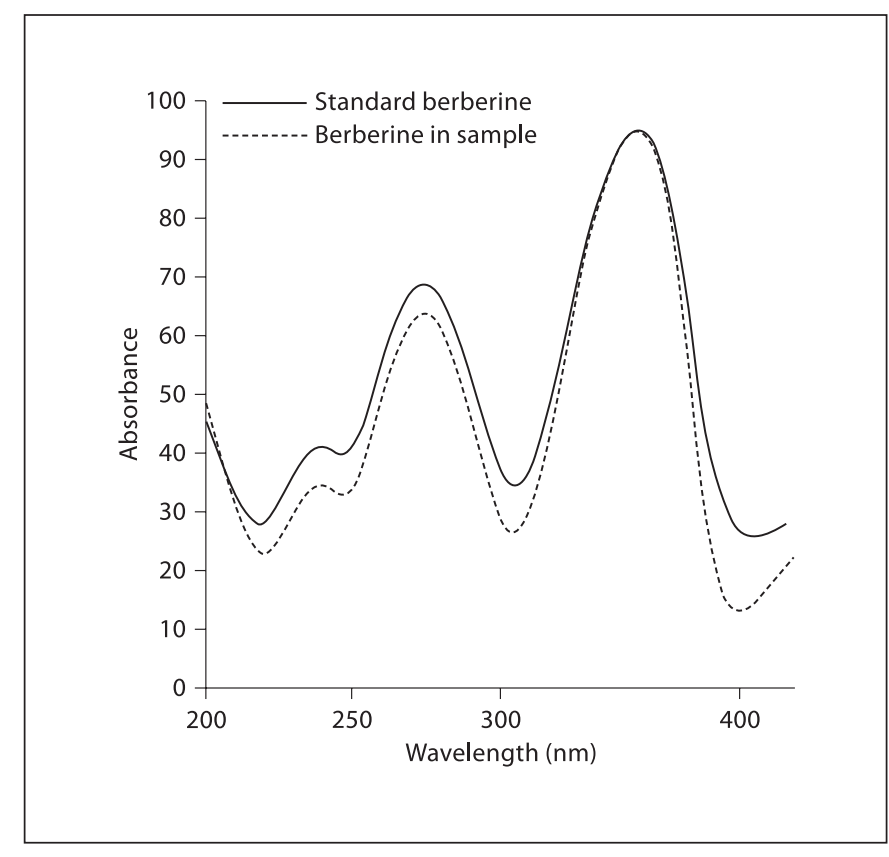

berberine (table 3). The UV spectrum of tested samples and standard berberine was found to overlap, indicating the purity of the spots (fig. 3). Accuracy of the data is presented in table 4 . Recoveries of standard berberine were within $97.58-98.71 \%$. The method was precise with the \%RSD of $1.54 \%$ for intraday precision and $1.42 \%$ for interday precision (table 5). The LOD and LOQ of berberine were 25 and $50 \mathrm{ng} / \mathrm{spot}$, respectively. 
Table 4. Recovery of berberine by the TLC-densitometric method $(\mathrm{n}=3)$

\begin{tabular}{llllll}
\hline Serial No. & $\begin{array}{l}\text { Amount of } \\
\text { berberine in the } \\
\text { extracts }{ }^{1}, \mathrm{mg}\end{array}$ & $\begin{array}{l}\text { Amount of } \\
\text { berberine } \\
\text { added, mg }\end{array}$ & $\begin{array}{l}\text { Amount of } \\
\text { berberine found } \\
\text { in mixture, mg }\end{array}$ & $\begin{array}{l}\text { Recovery } \\
\%\end{array}$ & $\begin{array}{l}\text { RSD } \\
\%\end{array}$ \\
\hline 1 & 223.56 & 198 & 416.76 & 97.58 & 0.28 \\
2 & 223.56 & 297 & 516.73 & 98.71 & 2.09 \\
3 & 223.56 & 396 & 610.92 & 97.82 & 3.80 \\
\hline \multicolumn{2}{l}{${ }^{1}$ Macerated with $80 \%$ ethanol. } \\
\hline
\end{tabular}

\begin{tabular}{llcc}
\hline \multirow{2}{*}{ Determination } & \multicolumn{3}{l}{ Area counts } \\
\cline { 2 - 4 } & 1st day & 2nd day & 3rd day \\
\hline 1 & $4,106.24$ & $3,948.54$ & $4,187.38$ \\
2 & $4,134.69$ & $3,812.69$ & $4,197.56$ \\
3 & $4,042.19$ & $3,964.39$ & $4,325.71$ \\
4 & $4,084.60$ & $3,909.61$ & $4,336.81$ \\
5 & $4,004.40$ & $3,939.52$ & $4,235.86$ \\
6 & $4,113.21$ & $3,980.94$ & $4,295.48$ \\
Mean $(\mathrm{n}=6) \pm \mathrm{SD}$ & $4,080.89 \pm 48.87$ & $3,925.95 \pm 60.48$ & $4,263.13 \pm 65.07$ \\
RSD, \% & 1.20 & 1.54 & 1.53 \\
\hline
\end{tabular}

Intraday precision $(\mathrm{RSD} \%, \mathrm{n}=6)=1.20-1.54$.

Interday precision $(\mathrm{RSD} \%, \mathrm{n}=3)=4.13$.
Table 5. Precision of berberine by the TLC-densitometric method at $396 \mathrm{ng} / \mathrm{spot}$

\section{Determination of Berberine Content in the Stem}

\section{Extracts}

The highest berberine yield $(3.37 \pm 0.30 \% \mathrm{w} / \mathrm{w})$ was obtained in the case of maceration with $80 \%$ ethanol while the lowest yield $(2.38 \pm 0.11 \% \mathrm{w} / \mathrm{w})$ was obtained by maceration with $50 \%$ ethanol (table 1), indicating that the maceration with $80 \%$ ethanol was the best method to obtain an extract rich in berberine.

The TLC-densitometric method was found to be accurate and precise for quantitation of berberine in the stem extract of C. fenestratum. This method has several advantages over the other analytical procedures, such as high-performance liquid chromatography (HPLC) [11, 12] and spectrophotometry $[13,14]$, such as simple pretreatment of samples, low cost, and a large number of samples that can be screened in parallel. However, some disadvantages were found such as the lower precision and sensitivity of the method compared to the HPLC.

\section{Conclusion}

The maceration with $80 \%$ ethanol was the suitable method to extract $C$. fenestratum stem due to the highest yield of the crude extract and berberine content. TLC fingerprints of the extracts from different extraction methods showed a similar pattern, and berberine was a major component.

\section{Acknowledgments}

This study was granted by the Royal Golden Jubilee PhD Program (PHD/0235/2544), Thailand. 


\section{References}

1 Dechwisissakul P, Bavovada R, Thonghoom P, Maison T: Pharmacognostic identification of Hamm. Thai J Pharm Sci 2000;24(sup$\mathrm{pl}): 31$.

2 Rungsimakan S: Pharmacognostic Property of Khamin khruea; Master's thesis Graduate School, Chulalongkorn University, 2001.

- 3 Namba T, Tsunnezuka M, Dissanayake DMRB: Studies on dental caries prevention by traditional medicines (part 3): Screening of Ayuravedic medicines for anti-plaque action. Shoyakugaku Zasshi 1985;39:146-153.

4 Hattori M, Nakabayashi T, Lim Y: Inhibitory effect of various Ayuravedic and Panamanian medicinal plants on the infection of herpes simplex virus-I in vitro and in vivo. Phytother Res 1995;9:270-276.

5 Ray PG, Majumda SK: Antimicrobial activity of some Indian plants. Econ Bot 1976;30: 317-320.
6 Palasuntheram C, Layer KS: Antimicrobial activity of Coscinium fenestratum Colebr. against Clostridium tetani. Indian J Med Res 1982;76:71-76.

7 Ingh GB, Singh S, Malhotra S: Hypotensive action of Coscinium fenestratum stem extract. J Ethnopharmacol 1990;30:151-155.

8 Keawpradub S: The Alkaloids from the Stems of Coscinium fenestratum (Gaertn.) Colebr.; Master's thesis Graduate School, Chulalongkorn University, 1992.

$\checkmark 9$ Pinho PMM, Pinto MMM, Kijjoa A, Pharadai K, Diaz JG, Herz W: Protoberberine alkaloids from Coscinium fenestratum. Phytochemistry 1992;31:1403-1407.

10 The European Agency for the Evaluation of Medical Products: ICH Topic Q2B Note for Guidance on Validation of Analytical Procedures: Methodology GPMP/ICH/281/95, 1996.
11 Abourashed EA, Khan IA: High-performance liquid chromatography determination of hydrastine and berberine in dietary supplements containing goldenseal. J Pharm Sci 2001;90:817-822.

12 Chu CY, Sheu SJ: Liquid chromatographic separation of the alkaloids in coptis-evodia herb couple. J Chromatogr A 1996;756:137144.

13 El-Masry S, Korany MA, Abou-Donia AH: Colorimetric and spectrophotometric determinations of hydrastis alkaloids in pharmaceutical preparations. J Pharm Sci 1980;69: 597-598.

14 Sreevidya N, Mehrotra S: Spectrophotometric method for estimation of alkaloids precipitable with Dragendorff's reagent in plant materials. J AOAC Int 2003;86:1124-1127. 